\title{
La construcción de puentes para una convivencia solidaria
}

\author{
Cristian Frutos Solé (Universitat de Barcelona)
}

Zygmunt Bauman. Extraños llamando a la puerta. Barcelona, Paidós, 2016, 112 p.

Zygmunt Bauman (1925-2017), filósofo, sociólogo y ensayista, ha sido uno de los autores clave del siglo XX. Además de desarrollar el concepto de «Modernidad líquida», a lo largo de su trayectoria ha escrito sobre una gran diversidad de temas, muchos de los cuales giran en torno al holocausto, la globalización, la modernidad, la posmodernidad y las clases sociales. Algunas de las obras en las que se ha materializado su pensamiento son: Modernidad y holocausto (1998), Vidas desperdiciadas: La modernidad y sus parias (2005) y Múltiples culturas, una sola humanidad (2008), habiendo recibido tres premios en 1989, 1998 y 2010. En Temps $d^{\prime} E d u c a c i o ́$ ', sus escritos han sido comentados en diversas ocasiones, circunstancia que confirma la relevancia de sus aportaciones para la educación y mejora de la sociedad.

(1) Enric Prats en su artículo «Pedagogia líquida per a una educació sòlida: a propòsit de Bauman», publicado en el número 28 y que puede encontrarse en el siguiente enlace:

http://www.raco.cat/index.php/TempsEducacio/ article/view/126412/176643

Xavier Laudo Castillo en su artículo «Pedagogies de la liquiditat», publicado en el número 30 y que puede encontrarse en el siguiente enlace: http://www.raco.cat/index.php/TempsEducacio/ article/view/128536/176879

Jordi García i Farrero en su artículo «Modernitat i barbàrie. A propòsit de 'Modernidad y Holocausto', de Zygmunt Bauman», publicado en el número 37 y que puede encontrarse en el siguiente enlace:

http://www.raco.cat/index.php/TempsEducacio/ article/view/186898/241884
El libro aquí reseñado versa sobre un tema que está presente en nuestro día a día: las migraciones masivas. En los seis capítulos en los que se divide, basándose en ejemplos y datos concretos, el autor plantea la necesidad de cambiar las políticas (de construcción de muros) que se han desarrollado alrededor de lo que se conoce como «crisis migratoria» por otras centradas en la construcción de puentes que, reconociendo nuestra interdependencia, fomenten la convivencia solidaria con esas otras personas que son consideradas extrañas. Solo así, comenta el autor, podremos salir de la crisis actual de la humanidad.

Bauman, haciéndose eco de las palabras que Flynn publicó en 2015, subrayaba que este «se recordará como el año en que el movimiento de entrada y salida de personas del país terminó por europeizarse de manera tan definitiva como indisoluble» (p. 84). Desde entonces, y aún en nuestros días, el número de «migrantes que llaman a las puertas de Europa» (p. 12) ha crecido inmensamente, «impelidos por el imperio de la violencia arbitraria a abandonar sus hogares y sus más preciadas pertenencias [o huyendo] para guarecerse de los campos de exterminio» ( $p$. 13), y sumándose a los llamados «inmigrantes económicos».

La situación actual que estamos sufriendo «quienes vivimos tras esas puertas» (p. 15) se caracteriza por «la desregulación progresiva de los mercados de 
trabajo y [...] la "flexibilización" del empleo» (p. 32). Esto contribuye, a su vez, a aumentar «la fragilidad de las posiciones sociales y la inestabilidad de las identidades socialmente reconocidas» (p. 32), además del precariado. Esta situación se agrava, asimismo, por la presencia del terrorismo yihadista. Todo ello favorece que este fenómeno (para nada nuevo) de las migraciones masivas produzca un sentimiento de inseguridad, incertidumbre e inquietud por ser (esos «extraños») «aterradoramente impredecibles» (p. 15).

En este sentido, Bauman nombra tres causantes de estos sentimientos hacia los migrantes: (1) «la ambivalencia permanente de la vida urbana» (p. 16); (2) el hecho de que esos «extraños entre nosotros» (p. 15) presenten unas condiciones peores que los propios marginados de la sociedad autóctona [entendiendo por marginados a aquellos que ya han perdido los logros o pertenencias o que nunca han tenido la oportunidad de conseguirlos] y (3) la presencia de un "precariado emergente, formado por personas que temen perder sus preciados y envidiables logros, posesiones y posición social» ( $p$. 20).

Con todo, a los políticos no les interesa «calmar las inquietudes ciudadanas [...] [sino] más bien cebar la ansiedad provocada por la incertidumbre del futuro y por la ubicua y constante sensación de inseguridad» (p. 32). Para ello, han desarrollado políticas de securitización, es decir, «[...] reclasificación en ejemplos de "inseguridad" de cosas que previamente se creían más propias de alguna otra categoría de fenómenos [...] seguida casi automáticamente de su transferencia al ámbito, la jurisdicción y la supervisión de los órganos de seguridad» (p. 28). De hecho, son políticas consistentes «en desplazar la preocupación ciudadana de problemas que los gobiernos son incapa- ces de manejar [...] hacia otros problemas en los que sí sea visible su compromiso y la efectividad (ocasional) de su gestión» (pp. 32 y 33). Entre los primeros están, por ejemplo, «la disponibilidad de empleos de calidad, la fiabilidad y la estabilidad de la posición social» (p. 33); entre los segundos, «la lucha contra terroristas que conspiran contra la integridad física y las pertenencias más preciadas de la gente corriente» (p. 33). A su vez, esta securitización «provoca la adiaforización de la cuestión de los migrantes, es decir, [...] hace que tanto ellos como lo que se les hace se abstraiga de toda evaluación moral» ( $p$. 36). $Y$ esto supone que estas personas pasen «a estar fuera del alcance [...] de la responsabilidad moral $y$, sobre todo, del espacio de la compasión y de aquello que nos impulsa a preocuparnos por las otras personas» (p. 36).

Otro aspecto negativo de la securitización es que facilita la labor de aquellos que reclutan a verdaderos terroristas, ya que «identificar el "problema de la inmigración" con el problema de la seguridad nacional y personal [...] está jugando a favor [...] de tres grandes intenciones interconectadas a Al Qaeda, Daesh y a sus futuras prolongaciones y seguidores» ( $p$. 39): (1) enardecer el antislamismo en Europa para que los jóvenes musulmanes víctimas de actos discriminatorios en los países de acogida "se convenzan de que la brecha [...] que separa a los inmigrantes de sus anfitriones nunca podrá cerrarse» (p. 39); (2) conseguir que sea inconcebible la comunicación y la interacción entre personas de diferentes culturas y (3) aprovecharse del poder de la estigmatización, ya que produce diferentes reacciones en las personas que la padecen: habrá quienes sufran una pérdida de autoestima, otros que perciban estos actos estigmatizantes como ofensivos $y$ 
merecedores «de una venganza» (p. 42) y, finalmente, quien

\begin{abstract}
«no vive "de acuerdo con lo que efectivamente exigimos de él", pero que, "aislado por su alienación, protegido por creencias propias sobre su identidad, siente que es un ser humano perfectamente maduro y normal, y que, por el contrario, nosotros no somos del todo humanos"» (p. 42).
\end{abstract}

Las personas que siguen este último patrón buscan algún grupo significativo que les ayude a convencerse de su «normalidad» «y que esté también dispuesto a admitirlas en su seno y a comprometerse a proteger colectivamente el estatus mejorado que ellas reclaman» (p. 43). A este tipo de personas es, precisamente, a las que buscan los reclutadores de terroristas por su situación de vulnerabilidad.

Seguramente muchas personas se hayan hecho una pregunta que Bauman también formula en este libro: «¿Quiénes son esos jóvenes que huyen de Europa para unirse a las huestes terroristas para luego regresar tras haber recibido instrucción en terrorismo?». Este autor aporta la respuesta de Pierre Baussand, según el cual «... la mayoría de conversos occidentales al Daesh proceden de entornos desfavorecidos» (p. 38). Ante las grandes dificultades que padecen en sus países, «muchos jóvenes europeos se sienten víctimas abandonadas a su suerte» (p. 39). $Y$ ese desempoderamiento «explica en parte el atractivo de la sensación de importancia y control que el Daesh infunde en sus partidarios» (p. 39). Precisamente estas actitudes coinciden con el tercer patrón de conducta relacionado con el estigma.

Actualmente, vivimos en un «estado de alerta constante» (p. 56) y los políticos sacan partido de ese miedo de los ciudadanos para ganar votos. «"[...] Cuando la sociedad se desmorona, la nación aparece como garantía final". "Ellos -los extran- jeros [...]- pueden y deben ser culpados de todas las quejas, incertidumbres y desorientaciones que tantos de nosotros sentimos» (p. 61). No obstante, como comenta Hobsbawm, en nuestras sociedades «las comunidades y los grupos étnicos están condenados a coexistir, sea cual sea la retórica de quienes sueñan con la vuelta de una nación sin mezclas» ( $p$. $60)$. Por tanto, como sociedad no podemos mantener una actitud pasiva mientras la situación actual va enquistándose cada vez más. Es necesario evitar posicionarse desde el nosotros contra ellos, generador de una creciente islamofobia, ya que los grupos terroristas aprovechan estos discursos para reclutar a personas.

Se ha acusado a estos extraños de «ser portadores de enfermedades terminales, estar al servicio de Al Qaeda o del "Estado Islámico" [...] o conspirar para convertir Europa al Islam e imponer la sharia como ley suprema» (p. 77), fomentando, así, su deshumanización, la cual «allana el camino para que se los excluya de la categoría de los legítimos poseedores humanos de derechos» (p. 78) y favoreciendo, a su vez, el proceso de securitización. «Michel Agier [...] sugiere que la "política migratoria" va dirigida a "consolidar una división entre dos grandes categorías mundiales cada vez más cosificadas: por un lado, un mundo limpio, sano y visible; por el otro, un mundo de restos residuales, oscuros, enfermos e invisibles"» (p. 82). Cuando Bauman habla de restos, se refiere «[...] a personas que han quedado ya excluidas de nuestro ámbito de visión, de interés y de conciencia» (p. 82).

Por tanto, como expone Bauman, hemos de trabajar conjuntamente para conseguir un entendimiento. Es decir, una «fusión de horizontes» (p. 102) mediante el diálogo ( $y$, más concretamente, «la conversación entre personas que vienen de diferentes modos de vi- 
da»(p. 104)), sustituyendo la hostilidad por la hospitalidad y entendiendo que «[...] las mayores armas que Occidente puede desplegar contra el terrorismo son la inversión, la inclusión y la integración sociales en nuestro propio territorio» ( $p$. 45).

En definitiva, la obra reseñada, y muchos otros escritos del mismo autor, exponen y comentan una visión de la realidad social que nos rodea. La necesidad de trabajar conjuntamente para contrarrestar los males producidos por el estigma (causado, en muchas ocasiones, por la vinculación de determinados actos, creencias o intenciones de una parte con el conjunto de un colectivo determinado) es de suma importancia para aproximarnos poco a poco hacia una sociedad más democrática e igualitaria. Así, para hacer frente al Gran Hermano que controla nuestra sociedad, es imprescindible construir puentes que favorezcan el acercamiento de las múltiples culturas que conviven en un mismo espacio. Una aproximación a través de la cual, probablemente, nos daríamos cuenta de que no somos tan diferentes como pensamos.

\section{Referencias}

Orwell, G. (2013) 1984. Barcelona, Debolsillo. 